\title{
EL DIÀLEG AMB IORGOS SEFERIS AL LLIBRE TRES SUITES DE CARLES MIRALLES
}

\author{
ERNEST MARCOS HIERRO \\ Universitat de Barcelona \\ emarcos@ub.edu \\ ORCID: 0000-0003-3378-4254
}

RESUM

Aquest article examina les traces del diàleg amb l'obra del poeta Iorgos Seferis (1900-1971), especialment del llibre Mithistòrima, en l'obra del poeta català Carles Miralles (1944-2015), que fou estudiós i traductor del Premi Nobel grec. A tall d'exemple, l'article analitza la presència d'elements i motius de la poesia de Seferis en el darrer llibre de Miralles, Tres suites, aparegut pòstumament l'any 2017.

PARAULES CLAU: Carles Miralles, Iorgos Seferis, poesia catalana contemporània, poesia neogrega del segle XX, literatura comparada.

\section{THE DIALOGUE WITH GIORGOS SEFERIS IN THE BOOK TRES SUITES BY CARLES MIRALLES}

\section{ABSTRACT}

This paper examines the traces of dialogue with the work of the poet Giorgos Seferis (19001971), especially the book Mythistorema, in the work of the Catalan poet Carles Miralles (19442015), who studied and translated the Greek Nobel Prize. By way of example, the paper analyses the presence of elements and motifs of Seferis' poetry in the last book by Miralles, Tres suites, which appeared posthumously in 2017.

KEYWORDS: Carles Miralles, Giorgos Seferis, Catalan contemporary poetry, modern Greek poetry of the twentieth century, comparative literature.

El novembre de l'any 2017 va aparèixer, com a número 165 de la col·lecció Poesia d'Edicions 62, el llibre Tres suites, el poemari pòstum de Carles Miralles (1944-2015), poeta i catedràtic de Filologia Grega de la Universitat de Barcelona. N'és curadora la seva vídua, Carmina Jori, i el presenta Jordi Cornudella amb un breu epíleg amb tres notes, que ofereix un repàs de tota la producció poètica de Miralles, iniciada el 1965 amb La terra humida, una col-lecció de poemes presentada al Premi Amadeu Oller de la Bordeta. ${ }^{1}$ A banda d'aquest text de Cornudella, ens informen també sobre les vicissituds de la seva trajectòria com a poeta les pròpies notes de Miralles i l'estudi introductori de Joaquim Molas a

\footnotetext{
${ }^{1}$ Miralles 2017: 65-70. La versió corregida i autoritzada d'aquest primer poemari apareix, tal com veurem a continuació, a Miralles 2002: 17-45.
} 
la publicació del recull D'aspra dolcesa. Poesia 1963-2001, aparegut el 2002.2 Gràcies a aquestes informacions podem reconstruir les fases diverses de la seva producció anterior a l'antologia esmentada.

Tenim, d'entrada, una primera etapa del període de 1966 a 1969, marcada, en paraules del mateix autor, per "la incontinència pròpia de la joventut" (Miralles 2002: 48). De tot aquest material en conservem només 34 poemes refosos i agrupats sota el títol comú de Manual de cosmologia en la secció corresponent de D'aspra dolcesa (2002: 47-101). A continuació, després d'un silenci gairebé total de quinze anys, arribà l'eclosió que suposà la publicació conjunta l'any 1981 de dos poemaris escrits simultàniament, Camí dels arbres i de tu (2002: 103-147) i Per fi la tortuga (2002: 149-166). Quasi una dècada després, el 1990, Miralles va retornar amb el seu llibre més elogiat per la crítica, La mà de l'arquer (2002: 167-183), i cinc anys més tard, el 1995, va publicar la seva particular celebració barcelonina intitulada La ciutat del plàtans.

Tal com indica Cornudella, l'aparició del seu poemari següent, Mans lentes d'aigua, dins de la compilació editada per Proa el 2002, fou una mica perjudicial per a la seva recepció, perquè "va tenir menys ressò del que segurament hauria tingut si hagués sortit tot sol a convidar els lectors" (Miralles 2017: 67). Miralles, tanmateix, sempre desitjós de presentar sota la forma coherent i rigorosa d'un llibre tant la seva obra de creació com l'acadèmica, va preferir integrar-lo com a obra inèdita al volum D'aspra dolcesa juntament amb un aplec d'"homenatges, poemes dedicats i de circumstàncies". A penes un lustre més tard, l'any 2007, va aparèixer No me n'he anat, una segona antologia de 87 poemes triats per nou lectors de la seva obra. Finalment, dos anys després, el 2009, el poeta presentà el darrer volum que va poder editar ell mateix, L'ombra dels dies roja, que mostra amb més claredat que cap altre llibre la dimensió política i social de la seva obra.

Com especifica la nota del mateix Carles Miralles (2017: 9) recollida a l'inici de Tres suites, la primera d'aquestes composicions neix d'un viatge seu a Palerm per assistir a un congrés de l'Istituto Nazionale del Dramma Antico durant la primavera de l'any 2012. Per aquesta raó, l'anomenà des de la seva concepció "Suite de Palerm", mentre que les altres dues, que adquiriren la seva forma definitiva al llarg de tot l'any 2013 i dels primers mesos de 2014, adoptaren també aquesta denominació, "Suite dels morts i dels dies" i "Suite del Roger", amb la idea -citem textualment- de coincidir "equívocament i irònica" amb un títol de Carles Riba. Tenim, doncs, en el títol mateix del recull una al·lusió literària evident a l'obra d'un poeta de referència indubtable per a Miralles. Convé tenir presents els treballs acadèmics que Miralles va dedicar a l'obra ribiana, des de l'article primerenc sobre la influència de Sòcrates i Jesús en el pensament del gran poeta, publicat al volum In memoriam Carles Riba

\footnotetext{
2 Vegeu el pròleg de Joaquim Molas a Miralles 2002: 11-15. Les notes de l'autor precedeixen totes les parts en què està dividit el volum.
} 
(Miralles 1973), fins al recull d'assajos aparegut el 2007 sota el títol Sobre Riba. No és difícil tampoc de reconèixer en el títol de la segona suite una altra al·lusió també "equívoca i irònica" als Treballs i dies d'Hesíode, un poema que Miralles també havia estudiat molt com a filòleg i historiador de la cultura grega arcaica. També s'hi endevina, certament, un eco del cèlebre llibre de Gabriel Ferrater Les dones $i$ els dies, que ja suposava, al seu torn, una paròdia del títol de l'aede ascreu. En Tres suites, tanmateix, la referència a autors i obres molt estimats no és un recurs puntual amb una intenció un punt iconoclasta, com podria semblar-ho a partir d'aquests dos únics exemples: ben al contrari, el diàleg permanent, implícit i explícit, amb la tradició literària prèvia és la base mateixa del llibre, construït amb l'estratègia complexa d'intertextualitat que caracteritza tota l'obra poètica de Miralles.

Com ho demostren, en efecte, per citar només dos exemples del seu darrer llibre de crítica literària Sobre Espriu, els seus estudis sobre La pell de brau (2013: 265-304) i Setmana Santa (2013: 305-313), Miralles, com a lector, tractava sempre de descobrir en els poemaris una estructura de sentit global, que construïa sovint en les seves anàlisis a través del reconeixement i la identificació de la presència dels elements recurrents de la tradició poètica prèvia. En aquest sentit, Miralles es mostrava com un crític literari molt pròxim a l'ideal definit per un altre dels seus poetes i homes de lletres preferits, T. S. Eliot, és a dir, com un lector d'experiència dilatada $\mathrm{i}$ amb la sensibilitat, els coneixements i l'ofici d'un filòleg. Si com a lector dedicava tanta atenció a la comprensió de l'estructura de l'obra aliena a partir de la presència de referències intertextuals, ens sembla lícit inferir que també posava una cura similar a l'hora d'emprar-les per a la construcció de l'obra pròpia. Per això, d'acord amb el seu exemple, resseguirem els ecos i les al-lusions perceptibles en Tres suites a fi de veure quin paper els correspon en la intel·lecció d'aquesta obra pòstuma.

Comencem per l'estructura general del llibre, fent atenció a les seves dimensions i proporcions. La primera suite, la "Suite de Palerm", i la tercera, la "Suite del Roger", estan constituïdes per vuit poemes cadascuna, mentre que la suite central, la "Suite dels morts i dels dies", en comprèn dotze, un dels quals és un tríptic; podem dir, per tant, que el conjunt suma catorze. Així, la seqüència, amb una voluntat clarament simètrica, és la següent: $8+12 / 14+8$. Segons la nota del mateix autor esmentada més amunt, aquesta proporcionalitat de les tres parts resulta reforçada per la interconnexió dels temes que cadascuna tracta. Diu Miralles que la primera suite és "sobre el temps i l'espai; sobre el passat en el present; sobre recomençar i estimar; sobre la veritat i l'amor". En aquesta part, efectivament, el poeta retorna a una ciutat, Palerm, que havia conegut, ens diu, trenta anys abans, i, tot visitant alguns dels seus indrets més famosos -el Museu Arqueològic, la Cappella Palatina, la Piazza della Vittoria-, posa en relació, com veurem més endavant amb més gran detall, el passat antic, medieval i modern de la ciutat amb records i experiències íntimes seves. 
A la segona suite, la dels morts i dels dies, el tema és el temps i, per tant, la llum i la fosca, el fet de recordar i la naturalesa dels records, la mort i els morts i "doncs sobre la vida i els mortals". En aquesta part, conseqüentment, hi ha explícites i emocionades al·lusions a difunts estimats, com l'avi matern del poeta en el tríptic que li està dedicat (Miralles 2017: 39-43) i l'amic Isidor Cònsul en el poema sobre el Virvio de Cesare Pavese (35-36). També hi trobem, entre d'altres, dos poemes sobre dues pintures de Diego Velázquez que Miralles admirava especialment, el Crist en la composició que comença amb el vers "Les urpes dels teus ulls meravellades" (32) i Les filoses en el poema titulat "Els tres nivells del real" (44-45). En la darrera suite, finalment, dedicada al seu fill Roger, el poeta parla sobre l'espai, "sobre com el pensen, el construeixen i el signifiquen la pintura [Giotto en el primer poema, que comença pel vers “L'amable sol d'hivern" (51-52)], l'escultura [el tercer poema “I l'escultor va obrar" (55)], l'arquitectura [el poema cinquè "Amb fustes de colors els nens aixequen" (57)] i l'art de la poesia [el segon poema "Trobo en la traducció" (5354) i el setè "Una muralla heptagonal circumda" (59-61)]". L'exposició d'aquest entramat de temes significatius palesa clarament el paper clau que la literatura $i$ l'art tenen en aquest llibre com a eines d'interpretació de la realitat. En els casos que hem esmentat dels poemes sobre el Crist de Velázquez i sobre Virbio / Hipòlit, l'evocació dels precedents literaris de Miguel de Unamuno i Cesare Pavese és patent $i$, per tant, podem considerar-los mostres d'una intertextualitat explícita. Per contra, en altres poemes les al·lusions no són tan transparents i per això podem parlar, segons la nostra opinió, de referències intertextuals semiexplícites i implícites.

Considerem referències semiexplícites dos passatges en els quals Miralles al-ludeix de manera imprecisa a dos textos que l'han commogut com a lector i li han inspirat, com a conseqüència, els poemes que escriu. En el primer cas, es tracta del poema que clou la "Suite dels morts i dels dies" intitulat "Un breu instant entre els teus dits fulgura". ${ }^{3}$ Des d'aquesta posició estratègica del conjunt, constitueix una evocació de la condició fugissera de la vida, que remarca en la seva conclusió el "guany" que la poesia comporta en els moments de desolació major. Així, en el vers onzè, el poeta fa referència a "un poema xinès" en el qual un home vidu es plany per la mort de la seva esposa, mentre distribueix els seus vestits. Quan recorda compungit els dies de la seva joventut, diu Miralles que la tristesa li fa la companyia "que fan de vegades els versos". Aquest consol, tanmateix, ja no pot atènyer la dona morta, com tampoc no podrà atènyer el lector quan sigui difunt. L'autor del poema al·ludit és Yuan Zhen (779-831), un dels poetes del període de la Dinastia Tang. El text en qüestió és la segona de les tres "elegies", com es denominen usualment a Occident, dedicades a la seva muller, morta en plena joventut després d'una

\footnotetext{
3 "Hi ha un poema xinès en què ell es queixa / que va donant els vestits d'ella, / que és morta, $\mathrm{i}$ ell recorda / quan eren joves i pobres tots dos / i estaven junts" (Miralles 2017: 46-47).
} 
vida d'insatisfaccions. Miralles potser el va llegir en la traducció castellana de Paulina Huang i Carles del Saz-Orozco (1983: 176) en un volum sobre la poesia d'època Tang publicat l'any 1983 a la sèrie Selecciones de Poesía Universal de l'editorial Plaza \& Janés.

La segona referència semiexplícita a un altre poema apareix en la segona composició de la "Suite del Roger". ${ }^{4}$ Miralles diu que l'ha llegit en traducció, indica que l'autor és "un antic poeta persa molt cèlebre" i en fa, a continuació, la glossa, tot desenvolupant l'afirmació que "en el tron celestial / són rossinyols els poetes". Es tracta d'un fragment del pròleg del primer llibre del Quintet de novel-les del poeta Ibn Yusuf-Nizamí (1141-1209), el volum intitulat Makhzan alasrar, el "tresor de misteris". La font de Miralles és la traducció al grec modern d'aquest passatge en un llibre del filòleg Panagiotis Agapitós sobre la novel·la amorosa en època medieval a Pèrsia, Bizanci i Occident, publicat a Atenes l'any

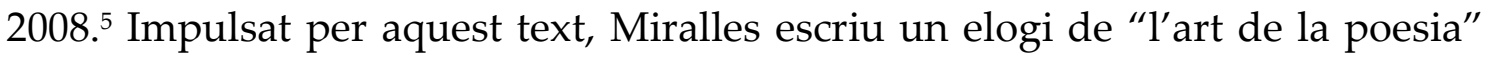
com a manifestació del sagrat i "mirall de la saviesa".

En aquests passatges, a través de la figura del lector commogut, que remet a un altre poeta molt estimat per Miralles, el gran alexandrí Konstandinos P. Kavafis, el recurs a la intertextualitat és patent, encara que no es produeixi la identificació explícita del text al·ludit. L'autor es limita a indicar a quina tradició pertanyen les seves fonts -la xinesa i la persa- i assigna al seu lector la tasca de localitzar-los. En altres poemes, tanmateix, no disposem d'aquestes pistes i, per això, podem parlar, com hem fet més amunt, de referències implícites, omnipresents, per bé que no declarades. L'objectiu d'aquest article és analitzar la presència intertextual més poderosa en aquest poemari: el diàleg implícit de Carles Miralles amb l'obra de Iorgos Seferis, el primer Premi Nobel de Literatura neogrec, nascut a Esmirna l'any 1900 i mort a Atenes el 1971.

Les raons de l'interès de Carles Miralles per Iorgos Seferis estan exposades amb precisió i eloqüència en el pròleg de la seva traducció de Mithistòrima (Miralles 1980: XI-XXXI), la primera gran obra del poeta neogrec, apareguda a Quaderns Crema l'any 1980. La tardor de 1964, quan encara era estudiant de Filologia Clàssica, Miralles va conèixer personalment el Premi Nobel durant una seva visita a Barcelona. La trobada amb aquest home que feia l'efecte -diude viure sota el pes aclaparador de la tristesa (Miralles 1980: XII) va impressionar molt el poeta i filòleg incipient, que en els anys immediatament posteriors va llegir i rellegir amb gran atenció els poemes de Seferis en el grec original i en traduccions franceses i angleses. El fruit més evident d'aquesta

4 “Trobo en la traducció / d'un poema o d'un fragment / de poema d'un antic / poeta persa molt cèlebre / l'afirmació, ben neta, / que en el tron celestial / són rossinyols els poetes" (Miralles 2017: 53-54).

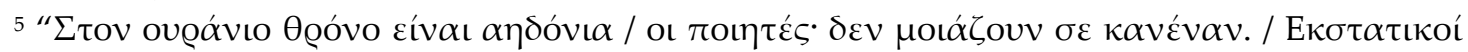

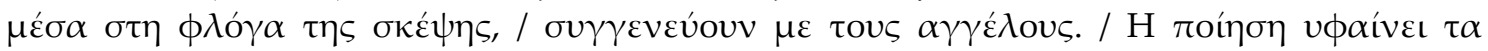

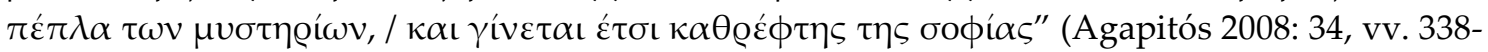
343). 
dedicació és la versió de Mithistòrima ja esmentada, amb un estudi preliminar i notes, però la influència de l'autor grec també és perceptible en la producció poètica de Miralles de la seva primera època. En la darrera secció de poemes del recull Manual de cosmologia, dins l'antologia D'aspra dolcesa, hi apareixen temes i imatges evocadores de Seferis: les travessies marítimes destinades a naufragar (Miralles 2002: 88-89, 96-98), l'episodi de la vékvı $\alpha$ de l'Odissea amb la invocació de Tirèsias (90) i del fantasma també homèric d'Elpènor (92-93), ${ }^{6}$ l'alternança en $^{2}$ l'ús de les primeres i segones persones poètiques del singular i del plural, i la construcció d'un paisatge poètic mediterrani de platges i de pinedes, molt característic també del poeta d'Esmirna. En aquests textos, Seferis no és l'únic poeta evocat, perquè també hi apareixen, i, fins i tot, més explícitament al·ludits, Kavafis (91) i Espriu (94-95), dues altres grans referències per a Miralles, però la seva importància com a principal interlocutor de l'autor és indubtable. També ens és fàcil reconèixer la seva presència en els dos poemaris apareguts el 1981 que Miralles va escriure durant els anys setanta, mentre preparava la seva traducció de Mithistòrima, és a dir, en el poema inicial i en els d'imatgeria més hel-lènica de Camí dels arbres $i$ de $t u^{7}$ i en l'estructura general i en alguns textos concrets de Per fi la tortuga (163-165).

Després d'aquesta fita notable, el diàleg amb Seferis va persistir en la dècada següent, que Miralles va dedicar precisament en bona part a la lectura i traducció dels autors més importants de la tradició poètica neogrega. En efecte, el juny de 1988 va aparèixer, a la col-lecció de les millors obres de la literatura universal del segle XX que publicaven Edicions 62 i La Caixa, l'antologia intitulada Set poetes neogrecs, que comprenia la traducció de poemes d'Andreas Kalvos, Dionísios Solomós, Kostís Palamàs, Konstandinos P. Kavafis, Àngelos Sikelianós, Iorgos Seferis i Odisseas Elitis. Per a aquest aplec, realitzat amb la col·laboració de Montserrat Camps, Miralles va fer una tria exemplar de l'obra de Seferis: una desena de poemes representatius del to i de l'estil de Mithistòrima, les dues "Gimnopèdies" dedicades a Sandorini i a Micenes, els cinc textos del cicle "El senyor Estratis el mariner", set poemes en total extrets dels tres volums dels Diaris de bord i, com a conclusió, el "Solstici d'estiu" sencer, el darrer dels Tres poemes secrets, l'última col·lecció poètica de l'autor grec, apareguda el 1966 (Miralles 1988: 113-156). En el pròleg del volum, a més, Miralles (1988: 14) va deixar escrit el seu elogi millor del mestre, l'autor que aspira amb la seva obra "a dir, a ser tot el món, tot allò que és i es pot dir: no pas en forma de catàleg o de riu, sinó en la seva essencialitat més nua". No és pas gaire diferent, a parer nostre, l'aspiració del poemari potser més madur i reeixit, segons les opinions de Joaquim Molas i Jordi Cornudella, de l'obra de Miralles (2002: 167-207), La mà de l'arquer, escrit en aquesta mateixa època i publicat el 1990. ${ }^{8}$ Pagaria la

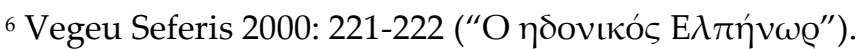

7 Miralles 2002: 105, 107, 115-116, 120-121.

${ }^{8}$ Vegeu el comentari de Molas a Miralles 2002: 11 i el de Cornudella a Miralles 2017: 67.
} 
pena resseguir també en aquest llibre les traces de Seferis o en els tres poemaris posteriors, La ciutat dels plàtans, arbre molt estimat per l'autor grec, Mans lentes d'aigua i L'ombra dels dies roja, però ens concentrarem en l'anàlisi anunciada de Tres suites.

El més pròxim en aquest llibre a una al-lusió explícita a Seferis és el comentari que encapçala el poema "Illa nua i silenci i cru febrer" de la segona suite (Miralles 2017: 29-30). En aquest text publicat entre parèntesis, Miralles copia els dos versos inicials del poema "Faim" d'Arthur Rimbaud, que pertany a la col-lecció Una temporada en l'infern: "Si j'ai du goût, ce n'est guère / que pour la terre et les pierres". El passatge citat ressona en els primers versos del nou poema: “La meva gana menja / només l'aire encerclat sota el cel gris, / pels carreus imponents d'alta mirada". Miralles, que evoca aquí una seva estada al port de Maó, precisa que l'illa que ara, en el seu text, és Menorca havia estat abans en una obra innominada Sandorini. El nom modern de l'antiga Tera és la pista que ens condueix a Seferis, que va triar precisament aquests mateixos versos de "Faim" per a l'íncipit de Mithistòrima. És evident, doncs, la voluntat de remetre el lector a l'univers poètic seferià, establint un vincle entre el seu paisatge de l'Egeu, assimilat a la tradició "infernal" de Rimbaud, i l'illa menorquina, on Miralles experimenta, per contra, un "àlgid i fred desig de viure", que el fa sentir-se "a recer del record inclement" dels versos dels seus precursors francès i grec.

Proveïts d'aquesta pista, és ara més fàcil reconèixer en la mateixa "Suite dels morts i dels dies" altres ecos de l'obra de Seferis, especialment en el poema que li serveix d'obertura, presidit per una cita en llatí de l'Apocalipsi de Joan (Miralles 2017: 27). El text descriu, amb tota probabilitat, una escena matinal, aparentment intranscendent, $\mathrm{amb}$ un temps molt rúfol, a la localitat empordanesa de Vilacolum, on Miralles tenia la seva casa de vacances. La segona persona interpel-lada en el poema recorda l'amenaça apocalíptica mentre camina per la vila, però no troba enlloc l'àngel profetitzat que ha de marcar amb el seu signe els qui han de salvar-se de la destrucció. Proposem reconèixer aquí dues al·lusions implícites a Seferis: d'una banda, a la seva cèlebre traducció al neogrec del Llibre de la Revelació apareguda el 1966 i, de l'altra, novament al poema inicial de Mithistòrima, on el subjecte col-lectiu del llibre espera absort l'arribada d'un missatger, un á $\gamma \gamma \varepsilon \lambda$ os en grec clàssic, que no compareix tampoc. No és casual, per tant, segons la nostra opinió, la ubicació d'aquest ésser també esquiu en el frontispici de la segona suite.

Trobem altres ecos de l'obra mestra de Seferis en altres poemes d'aquest recull -en el jardí on ploren les fulles del poema quart, ${ }^{9}$ en l'escena entre avi i nét de "En les teves mans de nen" $-{ }^{10}$ però la suite en la qual és més patent el diàleg amb el poeta grec és la primera, l'evocació del viatge a Palerm amb

\footnotetext{
${ }^{9}$ Miralles 2017: 31, eco de Seferis 1980: 9; 2000: 49.

${ }^{10}$ Miralles 2017: 39, eco de Seferis 1980: 21; 2000: 64.
} 
l'anàlisi de la qual clourem el nostre estudi. Tal com hem indicat més amunt, en aquesta secció Miralles construeix el seu discurs sobre el temps i l'espai a partir de les impressions que li va causar una estada a Palerm durant la primavera de l'any 2012. ${ }^{11}$ A l'impacte del viatge actual s'hi afegeix el record d'una visita trenta anys abans a la capital siciliana i, a més, les rememoracions de dos altres periples: una excursió a Perpinyà, "el nord més extrem de la llengua", i una travessia marítima de retorn, tal vegada de les Balears. En la seva nota introductòria, Miralles ens adverteix de la importància de l'amor en aquesta suite, concebuda i realitzada en un moment d'absència de la companya estimada, que esdevé, tanmateix, present en l'evocació dels viatges passats i en la prefiguració final del feliç retrobament al domicili de Barcelona. Seguint l'exemple de T. S. Eliot en les seves evocacions de paisatges significatius a Quatre Quartets, Palerm ofereix al poeta l'escenari ideal per viure-hi "un moment dins i fora dels temps", un punt de confluència del passat, el present $\mathrm{i}$ el futur individual i collectiu, en el qual al costat del Premi Nobel angloamericà compareix també el seu col-lega i amic neogrec. ${ }^{12}$

En efecte, ja des del primer poema, "Hi ha feres d'altres temps, a hores d'ara increïbles", que va guanyar el Premi extraordinari Memorial Salvador Espriu dels Jocs Florals de Barcelona de l'any 2013, Miralles (2017: 13) hi introdueix un tema molt car per a Seferis, la poesia que emana dels objectes funeraris antics exhibits als museus, instruments privilegiats de retrobament amb els qui ens han precedit. ${ }^{13}$

Aquesta línia prossegueix en el text següent, "El nen que suaument decanta", sobre la làpida de la tomba d'un infant, Filòcrates, que ens porta, a més, a la memòria el cèlebre poema "En el mes d'Athir" de Konstandinos P. Kavafis. ${ }^{14}$ Com en aquell cas, el poeta que visita tal vegada el Museo archeologico regionale Antonio Salinas de Palerm experimenta davant la vella tomba, per pura empatia humana, el dolor dels parents i dels amics d'aquell nen difunt, en el qual "grans esperances devien haver estat posades".

En el tercer poema, el viatger, mentre pren la fresca a la terrassa de l'hotel, recorda una paràbola del Buda, acollint-se també a la tradició poètica neogrega (Miralles 2017: 15). Quan Miralles, en efecte, parla aquí de la “impertorbable

11 Paga la pena recordar que l'onze de desembre de 2012, és a dir, mesos després d'aquesta estada, Miralles va impartir una conferència sobre l'obra de Seferis intitulada “...i la terra i les pedres" a la Residència d'Investigadors de Barcelona, dins d'un cicle organitzat per l'Associació Catalana de Neohel-lenistes.

12 La cita en la traducció catalana d'Àlex Susanna és de la secció cinquena del tercer quartet, “The Dry Salvages" (Eliot 2010: 98-99). Cal remarcar que Miralles (2008: 80-83) emprà Seferis per a la interpretació d'Eliot.

13 Vegeu, per exemple, la màscara micènica d'or del rei d'Asini al poema “O $\beta \alpha \sigma \iota \lambda \iota \alpha \varsigma \tau \eta \varsigma$

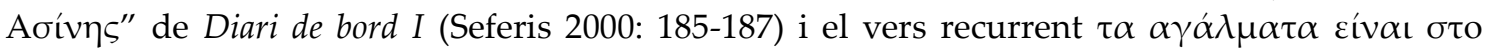

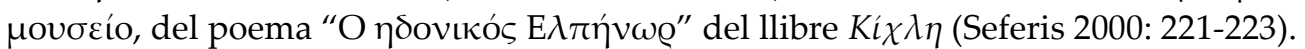

14 Miralles 2017: 14. Vegeu Kavafis 1975: 87-88. També cal recordar que Miralles (2008: 78) fa ús de Seferis per a la seva interpretació de Kavafis. 
serenor" de l'Il-luminat, al·ludeix sens dubte a la seva traducció prèvia del darrer vers del poema "El suïcidi d'Atzessivan, deixeble de Buda" d'Àngelos Sikelianós, on proclamava la "divina impertorbabilitat" de l'ànima de l'asceta (Miralles 1988: 105). D’altra banda, "serenor" -en l’original neogrec $\gamma \alpha \lambda \eta ́ v \eta-$ és una paraula clau del lèxic de Seferis a Mithistòrima, per la qual cosa podem concloure que en el sintagma citat del tercer poema ressonen les veus agermanades dels poetes de Lèucada i d'Esmirna.

La passejada pels carrers de Palerm del quart poema, que comença amb el vers "Del llevant a la posta, un carrer", suscita en el viatger solitari el record de l'estada prèvia a la ciutat, acompanyat per la dona estimada (Miralles 2017: 1617). Ella és la figura central d'una evocació del temps passat, que inclou també un grup d'amics. En els darrers versos, l'esment de la "sang per a l'evocació" palesa el parentiu d'aquesta escena amb el famós passatge de la vékvı $\alpha$ de l'Odissea, la davallada a l'Hades, present ja, com hem vist abans, a Manual de cosmologia i capital per a l'estructura de Mithistòrima. També ens recorda aquest llibre de Seferis el vers "Sota el cel que les muntanyes sostenen", que conté amb tota versemblança una al·lusió a l'inici del seu poema X: "La nostra terra és closa, plena de muntanyes / que tenen com a sostre el cel baix dia i nit" (Seferis 1980: 14; 2000: 55). També és perceptible en la descripció del paisatge urbà un eco del poema "Dies de juny del 41" del Diari de bord II, un homenatge molt personal de Iorgos Seferis (2000: 191) a la geografia mítica de l'Alexandria de Kavafis. Accentua, al nostre entendre, aquesta relació el fet d'identificar la ciutat de Palerm amb una illa "d'enyor i d'ombres evocades al seu bell centre", la memòria del poeta. En el poema de Seferis, precisament, es fa present en el paisatge alexandrí l'evocació d'una illa real, "deserta, poderosa i innocent", Creta, ocupada militarment en aquell moment pels alemanys.

En el cinquè poema de la suite, el diàleg amb Seferis esdevé encara més evident amb la introducció de l'emblemàtica Palinòdia d'Helena del líric arcaic Estesícor d'Hímera (Miralles 2017: 18). El poeta no ho explicita en cap moment, però en la glossa que dedica a la història de l'ídol de núvol que va provocar, segons Estesícor, la guerra de Troia, ressona la desesperació amarga de Seferis (2000: 239-242) en un dels seus poemes més admirats, "Helena" del Diari de bord III, denúncia eloqüent de la irracionalitat de totes les guerres. També veiem una al-lusió molt clara a Kavafis en l'hemistiqui "tan savi com t'has fet", que reprodueix exactament la traducció del poema "Ítaca" en la versió publicada per Miralles (1988: 69) a Set poetes neogrecs.

En el poema sisè, la vegetació de palmeres de la Piazza della Vittoria de Palerm porta a la memòria de l'autor la Plaça d'Aragó de Perpinyà, el nord més extrem de la catalanitat (Miralles 2017: 19-20). El viatger capta la bellesa familiar i quotidiana de l'entorn i registra la presència simultània de l'amor vital d'una jove parella d'adolescents i del record fúnebre d'un jove "tinent màrtir", Giuseppe Martino, caigut al camp de batalla el juny de 1918. Miralles utilitza el 
monument a l'heroi com una il·lustració pertinent dels estralls de la guerra lamentats en el poema anterior sobre l'Helena fingida d'Estesícor i Seferis.

A continuació, el poema setè descriu la visita a un altre lloc emblemàtic de la ciutat, la Cappella Palatina (Miralles 2017: 21). Amb els seus ulls d'home "gran embadalit", el visitant interpel-lat per la veu del poeta contempla els mosaics d'estil bizantí del temple i reconstrueix emocionat amb l'ajut de la seva memòria infantil les "velles contalles" de la història sagrada. Aquest interludi cristià, que ens porta a la memòria el darrer poema de Manual de cosmologia, ${ }^{15}$ fa pensar en les reflexions de Seferis (1981: 57-93) davant dels frescos de les esglésies rupestres de Capadòcia, que representaven per a ell la memòria més viva de Bizanci. En el poema de Miralles, per la seva banda, les imatges amarades d'ortodòxia de la Palatina són l'esperó per recuperar l'univers "imaginari" de la fe "cor seu endins".

Clou la suite el poema vuitè, aquell que presenta una estructura més complexa (Miralles 2017: 22-23). Hi compareixen, degudament datats, dos moments distints de la vida del poeta viatger. El més antic i el primer a ser esmentat és una travessia marítima nocturna de retorn "al camí dels arbres" compartit amb la companya estimada. Les referències a la vida engolida pel rastre del vaixell i a allò que encara en restava ens indueixen a situar aquest episodi en un període de tribulació personal, associat a la malaltia al·ludida en el títol del recull No me n'he anat. A desgrat d'això, no hi ha dubte de la joia del record, il·luminat per una "melanconia tan lúcida" i per l'alta claror que emana de l'estimada. Ara, en el retorn present de Palerm, el poeta contempla des de l'avió la llesca de mar per on viatjava anys enrere en el vaixell i constata la recuperació de la vida engolida l'altra vegada. L'ha aferrada i conservada, tal com proclamava també Seferis, després d'una gran crisi que el portà al llindar de la mort, en el seu cèlebre poema "Epifania 1937" del llibre Esbossos per a un estiu. ${ }^{16}$ Enfortit per "l'encesa certesa" de la mort adquirida en la ciutat visitada mitjançant els records personals $\mathrm{i}$ els vestigis del passat antic, medieval i modern de Palerm, el viatger retorna a casa per retrobar la seva dona, que és un arbre de fulles de plata i d'alta claror del viure segons la imatgeria lluminosa compartida també amb el poeta d'Esmirna. ${ }^{17}$ D'aquesta manera nítida i corprenedora, molt íntima, tal com la defineix Cornudella (Miralles 2017: 70), assoleix l'autor de la "Suite de Palerm" la serenitat que prometia el final de Mithistòrima: ${ }^{18}$ les obres de la mar, que són el viatge, i les obres de l'amor li han

${ }^{15}$ Miralles 2002: 101. Vegeu també la presència d'Adam i Eva al poema quart de la "Suite de Palerm" (Miralles 2017: 17).

16 "Kớ

17 Sobre aquesta imatgeria, vegeu la comunicació encara inèdita de Natalia Palomar "Árboles hombres desde Homero", presentada a les Jornades Internacionals sobre el Món Clàssic en homenatge a Carles Miralles que se celebraren a l'Institut d'Estudis Catalans de Barcelona els dies 18 i 19 de gener de 2018.

18 Seferis 1980: 28; 2000: 71. 
permès el retorn a la casa que l'espera, a "la inexplicable guspira de calidesa" que Miralles (1980: XI; 1988: 14) reconeixia en la poesia de Iorgos Seferis, aquell home trist i cansat que, dalt de Montjuïc, bevia amb els seus ulls lentament la mar.

\section{BIBLIOGRAFIA}

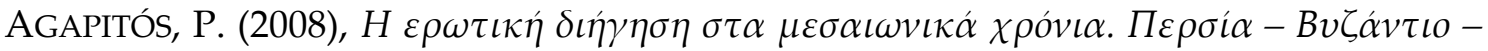
$\Phi \rho \alpha \gamma \kappa i \alpha$, Atenes, Agra.

ELIOT, T. S. (1943), Four Quartets, Nova York, Harcourt (trad. de Susanna, A. i pròleg de Gil de Biedma, J., Quatre Quartets, Barcelona, El cercle de Viena, 2010).

Huang, P. i Del SAZ-Orozco, C. (1983), Poetas de la Dinastía T'ang, Barcelona, Plaza \& Janés.

KAVAFIS 1975: vegeu SOLÀ 1975.

Miralles, C. (1973), "Sòcrates i Jesús, fites en l'evolució de Riba", dins In Memoriam Carles Riba (1959-1969), Barcelona, Ariel, 281-289.

MIRALLES, C. (trad.) (1980), Iorgos Seferis: Mithistòrima, Barcelona, Quaderns Crema.

Miralles, C. (1988), Set poetes neogrecs. Antologia: Kalvos, Solomós, Palamàs, Kavafis, Sikelianós, Seferis i Elitis, Camps, M. (col-1.), Barcelona, Edicions 62 / La Caixa.

Miralles, C. (2002), D'aspra dolcesa. Poesia 1963-2001, Barcelona, Proa.

MiRALLES, C. (2007), Sobre Riba, Barcelona, Proa.

Miralles, C. (2008), Sota el signe del fenix. Durar i pel foc sempre renéixer, Palma, Lleonard Muntaner.

MiRALLES, C. (2013), Sobre Espriu, Barcelona, Universitat de Barcelona.

MirAlLES, C. (2017), Tres suites, Jori, C. (ed.), Barcelona, Edicions 62.

SEFERIS 1980: vegeu MIRALLES 1980.

SEFERIS, I. (1981 [1974]),

SEFERIS, I. (2000 [1972]), Пoı $\mu \alpha \tau \alpha$, Atenes, Íkaros.

SolÀ, A. E. (trad.) (1975), Konstandinos P. Kavafis: Poemes, Barcelona, Curial. 